\title{
Effect of Shrimp Chitosan Coating on Physicochemical Properties and Shelf Life Extension of Banana
}

\author{
Md. Belal Hossain Sikder ${ }^{1,2} *$ Md. Muksitu Islam ${ }^{1}$, Shah Samiur Rashid ${ }^{2}$ and Md. Shakir \\ Moazzem ${ }^{1}$ \\ ${ }^{1}$ Department of Food Engineering and Tea Technology, Shahjalal University of Science and Technology, Sylhet \\ 3114, Bangladesh. \\ ${ }^{2}$ Faculty of Industrial Sciences and Technology, Universiti of Malaysia Pahang (UMP), Gambang-26300, Kuantan \\ Pahang, Malaysia. \\ "Email: belalustc@yahoo.com
}

\begin{abstract}
Banana is a highly perishable fruit with short shelf-life. Lack of proper preservation practices results in considerable amount of post-harvest loss of banana in Bangladesh. To minimize this post-harvest loss and extend the shelf-life of mature bananas (green colour) were treated with $0.5 \%, 0.75 \%$ and $1 \%$ chitosan coating and stored at room temperature $\left(28 \pm 2^{\circ} \mathrm{C}\right)$. The viability of the coating in extending the fruits shelf-life was assessed by evaluating total weight loss, ash content, total soluble solids $\left({ }^{\circ} \mathrm{Brix}\right), \mathrm{pH}$, titratable acidity (\%), disease severity and shelf-life during the storage period. Chitosan coating reduced respiration activity, thus slow ripening and the rate of decay reduces due to senescence. The chitosan-coated banana samples had a better outcome on weight loss, ash content, total soluble solids ( $\left.{ }^{\circ} \mathrm{Brix}\right), \mathrm{pH}$, titratable acidity $(\%)$ and disease severity values as compared to control samples. Banana coated with $1 \%$ chitosan exhibited less weight loss and reduced darkening than other samples. Disease severity was remarkably reduced by $1 \%$ chitosan coating application. Chitosan coating could extend the shelf-life of banana up to 16 days. This investigation showed that $1 \%$ chitosan was very effective in prolonging the shelf-life and quality of banana during the entire storage period.
\end{abstract}

Keywords- Banana, chitosan coating, shelf-life extension, natural privative, shrimp waste shell, postharvest loss.

\section{INTRODUCTION}

Banana (Musa sapientum L.) is a highly nutritious tropical fruit which is very popular and widely consumed all around the world. A decent amount of fiber, magnesium, sodium, potassium, phosphorus, iron and vitamin $\mathrm{A}, \mathrm{B}_{1}, \mathrm{~B}_{2}$ and $\mathrm{C}$ is present in banana [1]. It is one of the major fruits of Bangladesh and it is cultivated in huge amounts all over the country. It is the only fruit crop of Bangladesh that is available in the market throughout the year and its consumption rate is higher than any other fruits. Banana tends to ripen and mellow quickly after harvest. It is usually reaped at developing green stage and is stored at normal or low temperature. The overall production of banana in Bangladesh was 807,104 metric tons in 120,203 acres of cultivable land during 2016-17 [2]. Unfortunately, a huge amount of the harvested banana gets spoiled due to prevailing extreme temperature, humidity, inappropriate post-harvest handling and due to sub-optimal knowledge of post-harvest technology and preservation techniques. The post-harvest loss of banana in Bangladesh was recorded as 35\%-40\% from harvesting to consumption [3] and amounted to a financial loss of 299.15 crore taka (almost $\$ 35.405$ million USD) in 2016-17 [2]. The post-harvest spoilage of the banana fruits result in undesirable physiological changes, particularly loss of weight due to respiration and transpiration, loss of firmness and makes them vulnerable to microbial attack. Such spoilage can occur either during transportation or within the market resulting considerable financial loss to the cultivators, importers and retailers. Additionally, there is no established strategy for the producers and brokers of banana in Bangladesh to prolong the shelf life of banana. Consequently, a significant amount of harvested 
banana goes to waste due to its ephemeral nature. Besides, the low temperature preservation of banana is not feasible since it is sensitive to low temperature storage [4].

Edible coatings have long been used to preserve quality and extend shelf life of some fresh fruits and vegetables, such as citric fruits, apples and cucumbers [5]. Fruits or vegetables are typically coated by dipping in, brushing or spraying with a range of edible materials, in order that a semi permeable membrane is formed on the surface for suppressing respiration, controlling moisture loss and providing other functions [6]. Coatings can be developed from totally different components such as hydrocolloids (polysaccharides and proteins), lipids (waxes and resins) and synthetic polymers. Therefore, most coatings are made of more than one material with the addition of low molecular weight molecules including sorbitol, polyols or glycerol that serves as plasticizers. Even more than thermoplastic materials, edible films may have the potential for incorporation of further functional entities such as antimicrobials, antioxidants, flavours, and nutrients [7]. Chitosan is a high molecular weight and a linear polymer that is composed of $\beta-1,4$ linked $\mathrm{D}$-glucosamine with varying quantities and $\mathrm{N}$-acetyl $\mathrm{D}$-glucosamine residues. It is normally obtained by the alkaline digitization of chitin extract from hand abundant source of selfish (shrimp) exoskeletons or the cell walls of some microorganisms and fungi [8]. This biodegradable cationic polysaccharide has antimicrobial activity and excellent film-forming ability. This makes it articulately appropriate for the formulation of edible coating that has verified to be effective at extending the shelf life of fruits and vegetables [9]. Chitosan-based coating is effective in prolonging the shelf life and improving quality of fruits by dealing ripening, reducing respiration rate [10] reducing desiccation [11] regulating gas exchange decreasing transpiration losses modifying the internal atmosphere maintaining the standard of harvested fruits containing fruits fairness, firmness, weight, titratable acidity, soluble carbohydrates and Vitamin C and reducing mould growth [12]. Chitosan coating applied on fresh fruits showed reduced carbon dioxide evolution, loss in weight and titratable acidity. Moreover, the reducing sugar content and total soluble solids of coated fruit were lower than uncoated, suggesting that the former synthesized reducing sugars at a slower rate, having slowed down the metabolism [13].

The use of chitosan coating for maintaining quality and extending shelf life of fresh banana fruits has not yet been reported in Bangladesh till date to the best of our knowledge. Therefore, this present investigation was carried out to evaluate the efficiency of chitosan coating extracted from shrimp shell as a preservative to prolong the shelf life and maintain the quality of fresh bananas.

\section{MATERIAL AND METHODS}

\subsection{Collection of banana and shrimp:}

A total of $5 \mathrm{~kg}$ of green colored, oblong shaped and fully ripe bananas, with a rich sweet aroma and without any visual defects, were purchased from a local farmer of Sylhet, Bangladesh. The collected bananas were taken to the laboratory of Dept. of Food Engineering and Tea Technology and washed thoroughly in tap water to wash out adhering dirt and dust particles. On the other hand, $2 \mathrm{~kg}$ of shrimps (Macrobrachium rosenbergii) about $10 \mathrm{~cm}$ in size were collected from the local market of Sylhet, Bangladesh.

\subsection{Preparation of chitosan:}

The preparation of chitosan from shrimp waste shell is shown in figure 1 . At first, the head and skin of 2 $\mathrm{kg}$ of shrimps were isolated and collected using a sharp knife. The weight of the shrimp wastes was measured to be $700 \mathrm{~g}$. Then, the collected shrimp wastes were then washed with tap water and smashed with mortar pestle. Smashed shrimp waste was kept in polyethylene sacks at $28 \pm 2^{\circ} \mathrm{C}$ for $24 \mathrm{~h}$ in order to facilitate partial autolysis and subsequent chemical extraction of chitosan and to enhance the quality of chitosan [14]. Then isolation of chitosan was carried out using the following 3 (three) steps, namely demineralization, deproteinization and deacetylation. Finally, $30 \mathrm{~g}$ of chitosan was obtained from the shrimp waste shells. Demineralization and Deproteinization were done individually to remove protein and minerals from shrimp shell to get chitin. 


\subsubsection{Demineralization of shrimp shell:}

Demineralization of shrimp shell was achieved with $3 \%$ hydrochloric acid $(\mathrm{HCl})$ at room temperature $\left(28 \pm 2^{\circ} \mathrm{C}\right)$ with a solid to the solvent ratio of $1: 5(\mathrm{w} / \mathrm{v})$ for $16 \mathrm{~h}$ in demineralization stage [14]. The residue was washed and soaked in distilled water until $\mathrm{pH}$ level of 7.0 was obtained.

\subsubsection{Deproteinization of shrimp shell:}

Deproteinization of shrimp shell was done with $4 \%$ sodium hydroxide $(\mathrm{NaOH})$ at room temperature $\left(28 \pm 2^{\circ} \mathrm{C}\right)$ with a solid to the solvent ratio of $1: 5(\mathrm{w} / \mathrm{v})$ for $20 \mathrm{~h}$ [14]. The deposit was washed and soaked in distilled water until $\mathrm{pH}$ level of 7.0 was obtained. At that point, purified chitin was dried at $80^{\circ} \mathrm{C}$ until steady weight was acquired and it became crispy. Chitin flakes were grounded to little particles to facilitate deacetylation i.e. removal of acetyl groups from chitin.

\subsubsection{Deacetylation of chitin:}

Expulsion of acetyl groups from chitin was conducted by using $50 \%$ sodium hydroxide $(\mathrm{NaOH})$ at $65^{\circ} \mathrm{C}$

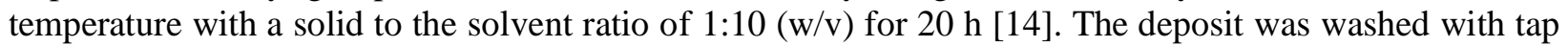
water until $\mathrm{pH}$ level of 7.0 was obtained. Then, it was dried at an oven dryer for $4 \mathrm{~h}$ at $65 \pm 5^{\circ} \mathrm{C}$ and was subsequently used for coating purposes.

The extraction of chitosan from shrimp waste shell is illustrated in the following flowchart:

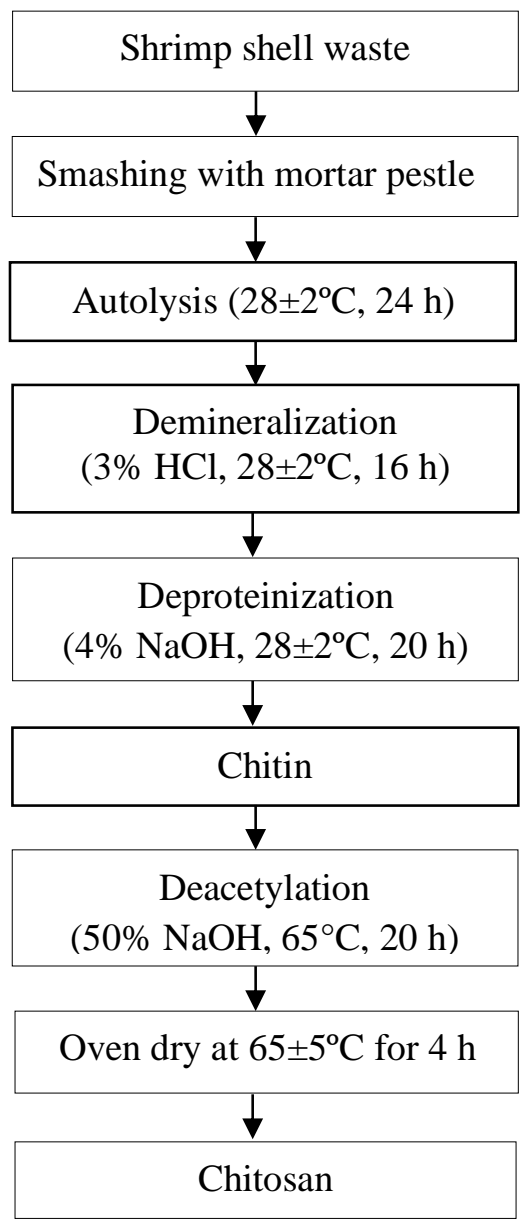

Figure 1: Flow chart showing extraction of chitosan from shrimp waste shell 


\subsection{Characterization of prepared chitosan}

\subsubsection{Moisture content (\%):}

Moisture content of the prepared chitin and chitosan was determined by the method of AOAC [15]. At first, weight of crucibles was measured and noted. $5 \mathrm{~g}$ of sample was taken in the crucibles. Again the weight of crucibles and sample was taken and noted. Then the crucible containing sample was kept in oven at $105^{\circ} \mathrm{C}$ for $24 \mathrm{~h}$. After heating, the dried sample was cooled in a desiccator. Weight of crucibles with sample was measured again until the weight become stable. Finally, moisture content $(\%)$ was calculated using equation (1).

$$
\text { Moisture content }=\frac{\text { Initial weight of sample }- \text { Final weight of sample }}{\text { The weight of the sample taken }} \times 100
$$

\subsubsection{Ash content (\%):}

Ash content was determined by the method of AOAC [15]. The sample was taken in a crucible and was heated with a spirit lamp until the sample was completely burnt and turned into ash color. Then the crucible was put in a muffle furnace at $600^{\circ} \mathrm{C}$ for about 3 to $5 \mathrm{~h}$. Then the sample was cooled in a desiccator and the weight of the crucible was noted down. The crucible was again heated in the muffle furnace for half an hour then cooled and weighed. This process was repeated until two consecutive weights were found to be same and the ash was almost white or greyish in color. Finally, ash content (\%) was calculated using equation (2).

$$
\text { Ash content }=\frac{\text { Weight of Ash }}{\text { The weight of the sample taken }} \times 100
$$

\section{3.3 Solubility in acid solution:}

The method of Puvvada et al. was used to measure the solubility of chitosan in acid solution [16]. $1.0 \mathrm{~g}$ of chitosan obtained from the deacetylation process was dissolved in $100 \mathrm{~mL}$ of $1 \%$ acetic acid solution and was mixed by a magnetic stirrer until a homogeneous solution was obtained. The acidic solution of chitosan was then filtered through a No. 2 filter paper $(55 \mathrm{~mm}$; Advantech, Tokyo, Japan). This procedure was repeated 3 times. The percentage of the solubility was calculated by using equation (3), (4) and (5).

Insoluble $(\mathrm{g})=$ final weight of filter paper $(\mathrm{g})$ - initial weight of filter paper $(\mathrm{g})$.

$$
\begin{aligned}
& \text { Insoluble }(\%)=\frac{\text { Insoluble }}{\text { The weight of the sample }} \times 100 \\
& \text { Solubility }(\%)=100-\text { insoluble }(\%) \ldots \ldots \ldots \ldots \ldots \ldots \ldots \ldots \ldots
\end{aligned}
$$

\section{3.4 Determination of degree of deacetylation:}

The degree of deacetylation (DD) was determined by the method described by Domard et al. with some modifications [17]. $0.1 \mathrm{~g}$ of chitosan was dissolved in $30 \mathrm{~mL}$ hydrochloric acid aqueous solution $(0.1 \mathrm{~mol} / \mathrm{l})$ at room temperature $\left(28 \pm 2^{\circ} \mathrm{C}\right)$ and 5-6 drops of methyl orange were added. Then, the red chitosan solution was titrated with $0.1 \mathrm{~mol} / 1$ sodium hydroxide solution until it turned orange. The degree of deacetylation (DD) was calculated by using equation (6). 


$$
\text { Deacetylation }(\%)=\frac{\mathrm{C}_{1} \mathrm{~V}_{1}-\mathrm{C}_{2} \mathrm{~V}_{2}}{\mathrm{M} \times 0.0994} \times 0.016
$$

\subsection{Formulation of chitosan coating and labelling of samples:}

The formulation of chitosan coating and labelling of samples are given in Table 1. Control samples, i.e., bananas not treated with chitosan coating, were labelled as Sample 1. 0.5\% chitosan coating was formulated by $0.5 \%$ chitosan solution $+0.6 \%$ acetic acid $+25 \%$ glycerol. Bananas treated with $0.5 \%$ chitosan coating were labelled as Sample 2. $0.75 \%$ chitosan coating was obtained by $0.75 \%$ chitosan solution $+0.6 \%$ acetic acid $+25 \%$ glycerol. Bananas treated with $0.75 \%$ coating were labelled as Sample $3.1 \%$ chitosan coating was produced by $1 \%$ chitosan solution $+0.6 \%$ acetic acid $+25 \%$ glycerol. Bananas treated with $1 \%$ chitosan coating were labelled as Sample 4. Then chitosan coated bananas were kept in room temperature $\left(28 \pm 2^{\circ} \mathrm{C}\right)$ for $2 \mathrm{~h}$ so that a thin layer of edible coating could be formed on the surface of the samples. When a visible thin layer of edible coating was formed after $2 \mathrm{~h}$ on the surface of treated samples, all the samples were stored in a room temperature of $28 \pm 2^{\circ} \mathrm{C}$ for further evaluation.

Table 1: Formulation of chitosan coating and labelling of samples

\begin{tabular}{ccccc}
\hline \multirow{2}{*}{ Samples } & \multirow{2}{*}{$\begin{array}{c}\text { Treatment of chitosan coating } \\
\text { on banana }\end{array}$} & \multicolumn{3}{c}{ Formulation of chitosan coating } \\
\cline { 3 - 5 } $\begin{array}{c}\text { Sample } 1 \\
\text { Control) }\end{array}$ & Untreated banana & Nil* & Nil* & Nil* \\
\hline Sample 2 & $0.5 \%$ chitosan coated banana & $0.5 \%$ & $0.6 \%$ & $25 \%$ \\
\hline Sample 3 & $0.75 \%$ chitosan coated banana & $0.75 \%$ & $0.6 \%$ & $25 \%$ \\
\hline Sample 4 & $1 \%$ chitosan coated banana & $1 \%$ & $0.6 \%$ & $25 \%$ \\
\hline & $*$ Nil = designated treatment has not been used in any form or concentration
\end{tabular}

\subsection{Physicochemical evaluation of samples during storage:}

\subsubsection{Determination of weight loss (\%):}

Determination of weight loss (\%) was estimated by the method of AOAC [15]. The samples were weighed by using a digital balance from the beginning to the end of the storage period at an interval of 4 days. The results were expressed as the percentage loss of initial weight by using equation (7).

$$
\text { Weight loss }=\frac{\text { initial weight-final weight }}{\text { initial weight }} \times 100
$$

\section{5.2 Determination of total soluble solids ( ${ }^{\circ}$ Brix):}

Total soluble solids $\left({ }^{\circ}\right.$ Brix) was determined by the method of AOAC by using an Abbe Hand Refractometer (ATAGO 9099, Japan) by placing a drop of juice on its prism [15]. The reading of total soluble solids was obtained as ${ }^{\circ}$ Brix from the direct reading of the refractometer.

\subsubsection{Determination of $\mathrm{pH}$ :}

The $\mathrm{pH}$ of the fruit was measured by the method of AOAC by using a pH meter (H1 98106, HANNA) at room temperature $\left(28 \pm 2^{\circ} \mathrm{C}\right)$ [15]. The sample was made into juice by blending $5 \mathrm{~g}$ of sample with $10 \mathrm{~mL}$ of water in a beaker. Then the $\mathrm{pH}$ meter was dipped into the beaker to measure the $\mathrm{pH}$ of the sample. 


\section{5.4 Determination of titratable acidity (\%):}

Titratable acidity (\%) was determined by the method of AOAC [15]. $5 \mathrm{~g}$ of sample was blended with 10 $\mathrm{mL}$ distilled water. Then the prepared mixture was filtered through a No. 2 filter paper $(55 \mathrm{~mm}$; Advantech, Tokyo, Japan). The extract was transferred to a $50 \mathrm{~mL}$ volumetric flask and the volume was made up to the mark with distilled water. $10 \mathrm{~mL}$ of extract was taken in a conical flask and titrated with $0.1 \mathrm{~N}$ sodium hydroxide solution just below the endpoint using phenolphthalein indicator. The titration was done three times for accuracy. Titratable acidity (\%) was calculated by using equation (8).

$$
\text { Titratable acidity }(\%)=\frac{\mathrm{T} \times \mathrm{N} \times \mathrm{V}_{1} \times \mathrm{E} \times 100}{\mathrm{~W} \times \mathrm{V}_{2} \times 1000}
$$

Where, $\mathrm{T}=$ Titration, $\mathrm{N}=$ Normality of sodium hydroxide, $\mathrm{V}_{1}=$ Volume made up, $\mathrm{E}=$ Equivalent weight of citric acid (64.38), $\mathrm{V}_{2}=$ Volume of the sample taken for estimation, $\mathrm{W}=$ Weight of sample

\section{5.5 Disease severity:}

Disease severity represents the percentage of the diseased portion of infected fruit and was measured based on eye estimation. Disease severity was scored as per the method described by Sivakumar et al. [17] using the following scale:

$1=0 \%$ of fruit surface rotten; $2=1-25 \%$ of fruit surface rotten; $3=26-50 \%$ of fruit surface rotten; $4=51$ $75 \%$ of fruit surface rotten; $5=76-100 \%$ of fruit surface rotten

\section{5.6 Shelf life:}

The shelf life of banana fruits as influenced by different postharvest treatments was calculated by visual observation and counting the days required to ripe fully as to retaining optimum marketing and eating qualities.

\subsection{Interval at evaluation of samples:}

The physicochemical properties of the samples namely weight loss (\%), total soluble solids ( $\left.{ }^{\circ} \mathrm{Brix}\right), \mathrm{pH}$, titratable acidity, disease severity and shelf life were evaluated at an interval of 4 days over a period of 12 days.

\subsection{Statistical analysis:}

Data were analyzed using SPSS software (SPSS Inc., Chicago, IL, USA), version 25 for Windows. Results of total weight loss $(\%)$, total soluble solids ( ${ }^{\circ}$ Brix $), \mathrm{pH}$, titratable acidity $(\%)$ and disease severity were reported as mean \pm standard deviation (SD) for three (3) replicates, $n=3$. One-way analysis of variance (ANOVA) followed by Duncan's multiple range test (DMRT) (multiple comparison post-hoc test) was used to analyze the statistical difference. Differences with p-values $<0.05$ were considered statistically significant.

\section{RESULTS AND DISCUSSIONS}

\subsection{Properties of prepared chitosan:}


The moisture content (\%), ash (\%), solubility (\%) and degree of deacetylation (\%) of the prepared chitosan were evaluated in triplicate, and the results with mean values and standard deviations are given in table 2. The moisture content (\%) of the chitosan was found to be $8.36 \pm 0.15 \%$ which complies with the findings of No \& Meyers [18] who reported that high-quality chitosan should have less than $10 \%$ of moisture content. The ash content $(\%)$ of chitosan was found to be $0.26 \pm 0.01 \%$. This finding is acceptable because highquality chitosan should have less than $1 \%$ of ash content [18]. Solubility (\%) of chitosan was found to be $97.00 \pm 0.02 \%$. This result is also acceptable because superior-quality chitosan should show higher solubility [18]. However, the solubility of chitosan is controlled by the degree of deacetylation and it is assessed that deacetylation must be at least $85 \%$ complete in order to achieve desired solubility in chitosan [18]. Degree of deacetylation (\%) was found to be $79.54 \pm 0.03 \%$ in prepared chitosan which is in agreement with the report of No \& Meyers [18].

Table 2: The properties of prepared chitosan extracted from shrimp shell waste.

\begin{tabular}{ccccc}
\hline No. of trials & Moisture $(\%)$ & Ash $(\%)$ & Solubility $(\%)$ & Degree of deacetylation $(\%)$ \\
\hline Trial-1 & 8.32 & 0.26 & 97.02 & 79.57 \\
\hline Trial-2 & 8.53 & 0.28 & 96.91 & 79.51 \\
\hline Trial-3 & 8.23 & 0.25 & 97.01 & 79.55 \\
\hline $\begin{array}{c}\text { Mean } \pm \text { standard } \\
\text { deviation }\end{array}$ & $8.36 \pm 0.15$ & $0.26 \pm 0.01$ & $97.00 \pm 0.02$ & $79.54 \pm 0.03$ \\
\hline
\end{tabular}

\subsection{Physico-chemical properties of treated banana:}

\subsubsection{Total weight loss (\%):}

The total weight loss $(\%)$ of the samples gradually increased over time. The effect of different chitosan coating on total weight loss (\%) during the storage period is illustrated in figure 1. As a post-harvest treatment, $1 \%$ chitosan coating demonstrated a significant effect (at $\mathrm{p}<0.05$ ) on reducing total weight loss $(\%)$ of banana than other chitosan treatments during the entire storage period (see figure 2). No weight loss ( $0 \%$ of weight loss) was found in any sample at the first day of storage (Day 0). On the 4th day of storage (Day 4), maximum weight loss was found in Sample 1 (26.5\% weight loss) while minimum weight loss was observed in Sample 4 (5.7\% weight loss). Comparatively higher weight loss was observed in Sample 1 (untreated bananas) which was recorded to be $7.4 \%, 16.5 \%$ and $26.5 \%$ at the 4th, 8th and 12th day of storage respectively, whereas comparatively lower weight loss was found in Sample 4 (1\% chitosan coated bananas) which was recorded to be 5.7\%, 9.4\% and $15.6 \%$ at 4th, 8th and 12th day of storage respectively. By the end of storage (at Day 12), the highest weight loss was observed in Sample 1 i.e. in untreated bananas (26.53\% weight loss) while the lowest weight loss was observed in Sample 4 i.e. in 1\% chitosan coated bananas (21.66\% weight loss). These results suggest that comparatively lower weight loss could be attributed to $1 \%$ chitosan coating. This finding is supported by the reports of Suseno et al. [19] and Maqbool et al. [20] confirming that about $30 \%$ weight loss can be achieved in $1 \%$ chitosan coated banana over a storage period of 12 days. The primary mechanism of weight loss from fresh fruits is by vapour-phase diffusion driven by a gradient of water vapour pressure between inside and outside the fruit leading to an enhanced transpiration process [19]. Shao et al. reported that chitosan coating minimized the weight loss of apples by reducing respiration rate [21]. Dang et al. also reported that loss of water could be effectively retarded in chitosan coated sweet cherries [22]. 


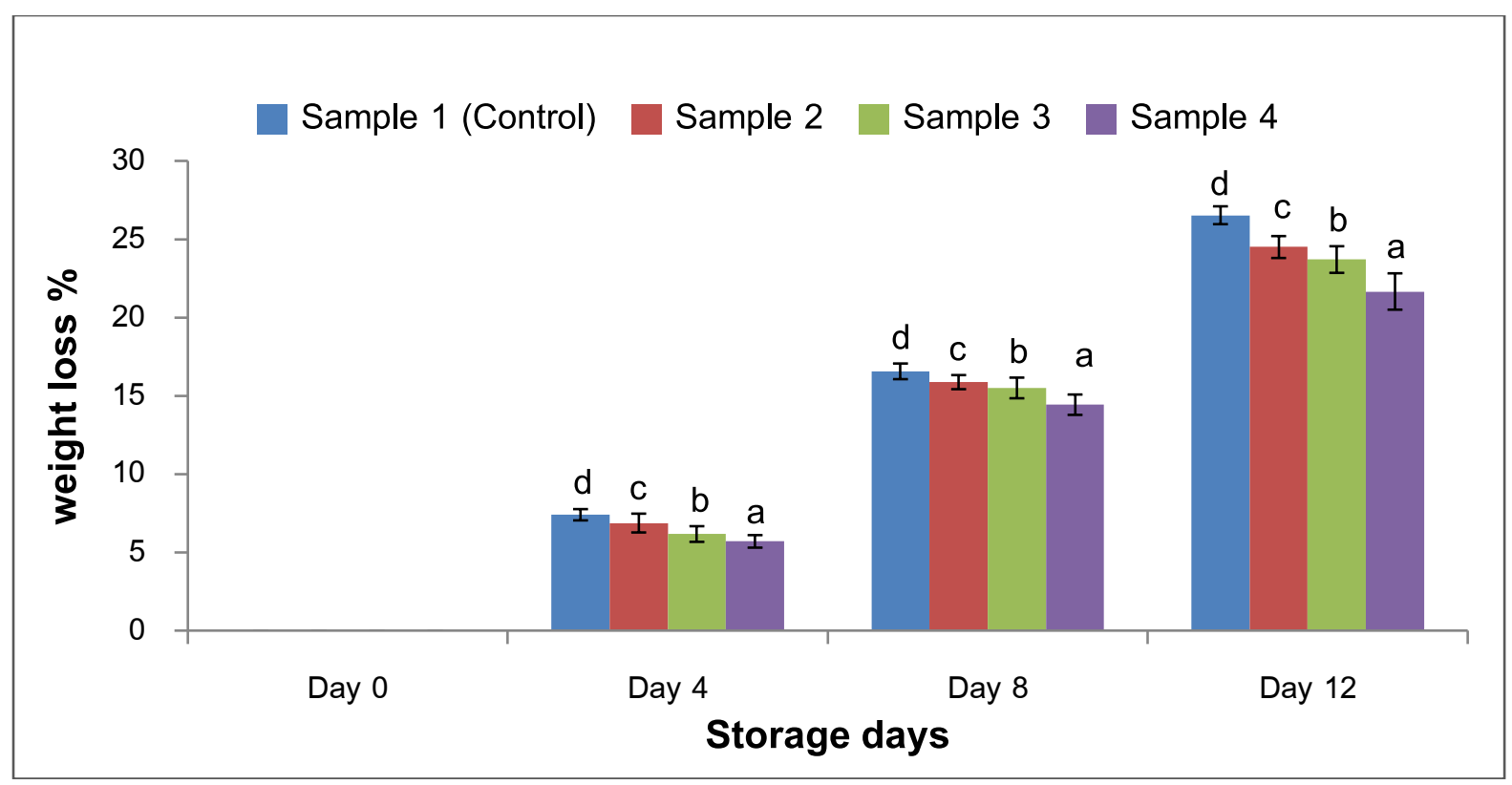

Figure 1: Weight loss $(\%)$ of samples at room temperature $\left(28 \pm 2^{\circ} \mathrm{C}\right)$; Values represent mean \pm standard deviation $(\mathrm{n}$ $=3$ ). Means with different letters are significantly different (at $\mathrm{p}<0.05)$

\subsubsection{Total soluble solids ( ${ }^{\circ}$ Brix):}

The total soluble solids ( ${ }^{\circ}$ Brix) of the samples gradually increased over time. The effect of different chitosan coating on total soluble solids during the storage period is depicted in figure 2 . As a post-harvest treatment, $1 \%$ chitosan coating demonstrated a significant effect (at $\mathrm{p}<0.05$ ) on retaining total soluble solids of banana than other chitosan treatments during the entire storage period (see figure 2 ). Total soluble solids ( ${ }^{\circ}$ Brix) was found to be $4.8{ }^{\circ}$ Brix for all samples at the first day of storage (Day 0). Comparatively higher retention of total soluble solids was observed in Sample 4 (1\% chitosan coated bananas) which was $10.27{ }^{\circ}$ Brix, $15.63^{\circ}$ Brix and $19.7^{\circ}$ Brix in the $4^{\text {th }}, 8^{\text {th }}$ and $12^{\text {th }}$ day of storage respectively, whereas comparatively lower retention of total soluble solids was observed in Sample 1 (untreated control samples) which was $15^{\circ}$ Brix, $24.5^{\circ}$ Brix and $26.6^{\circ}$ Brix in the $4^{\text {th }}, 8^{\text {th }}$ and $12^{\text {th }}$ day respectively. By the end of storage (at Day 12), the highest retention of total soluble solids was observed to be in Sample 4 i.e. $1 \%$ chitosan coated bananas $\left(19.7{ }^{\circ}\right.$ Brix $)$ while the lowest retention of total soluble solids was observed in Sample 1 i.e. in untreated control samples $\left(26.6^{\circ} \mathrm{Brix}\right)$. The increase in total soluble solids ( $\left.{ }^{\circ} \mathrm{Brix}\right)$ could be attributed the conversion of polysaccharides into simple sugars and the degradation of pectic substances in soluble solids during storage [23]. These results suggest that comparatively higher retention of total soluble solids of bananas could be obtained by applying $1 \%$ chitosan coating. This finding is consistent with the results reported by Ibrahim et al. [24]. Results of this study also suggests that an increase in chitosan concentration can successfully withhold the increase of total soluble solids in banana. This is due to the fact that chitosan coatings can provide a semi-permeable film around the fruit surface, which modifies the internal atmosphere by reducing oxygen and hoisting carbon dioxide levels, which diminishes the fruit respiration level and metabolic activity, hence, hinders the fruit ripening and senescence process [25]. A restrained respiration rate slows down the synthesis and the use of metabolites, resulting in lower soluble solids due to the slower hydrolysis of carbohydrates to sugars [26]. Similar observation was also made by Ali et al. who reported that chitosan coating viably deferred changes in total soluble solids concentration of papaya during 5 weeks of storage [27]. 


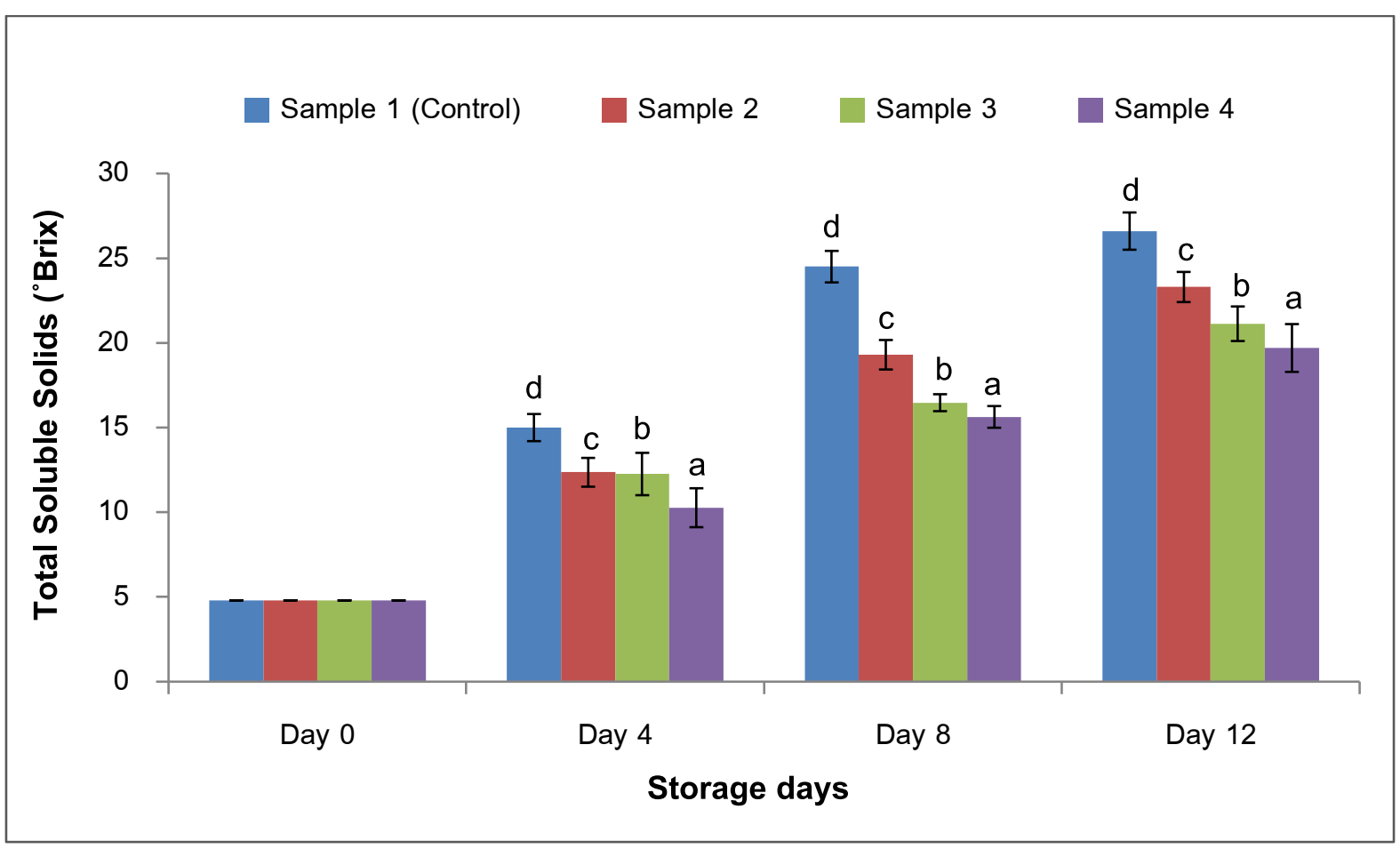

Figure 2: Total soluble solids ( ${ }^{\circ}$ Brix $)$ of samples at room temperature $\left(28 \pm 2^{\circ} \mathrm{C}\right)$; Values represent mean \pm standard deviation $(n=3)$. Means with different letters are significantly different (at $\mathrm{p}<0.05)$

\subsection{3 pH:}

The values of $\mathrm{pH}$ were observed to increase over time during the storage period of 12 days. The effect of different chitosan coating on $\mathrm{pH}$ during storage is shown in figure 3 . As a post-harvest treatment, $1 \%$ chitosan coating demonstrated a significant effect (at $\mathrm{p}<0.05)$ on retaining $\mathrm{pH}$ of bananas than other chitosan treatments during the entire storage period (see figure 3). $\mathrm{pH}$ of all samples at the first day of storage (Day 0) was found to be 4.31. Comparatively better retention of $\mathrm{pH}$ was observed in Sample 4 (1\% chitosan coated bananas) which was $4.58,5.09$ and 5.23 at the $4^{\text {th }}, 8^{\text {th }}$ and $12^{\text {th }}$ day of storage respectively. Control samples showed comparatively lower retention of $\mathrm{pH}$ than other samples which was 4.66, 5.17 and 5.31 at the $4^{\text {th }}, 8^{\text {th }}$ and $12^{\text {th }}$ day of storage respectively. By the end of storage (at Day 12), the highest retention of $\mathrm{pH}$ was observed in Sample $4(\mathrm{pH}=5.23)$ i.e. in $1 \%$ chitosan coated bananas while the lowest retention of $\mathrm{pH}$ was observed in Sample 1 i.e. in untreated control samples $(\mathrm{pH}=5.31)$. These results indicate that comparatively higher retention of $\mathrm{pH}$ of bananas could be obtained by applying $1 \%$ chitosan coating. This observation is in agreement with the results reported by Ibrahim et al. [24]. It should be noted that a little change in $\mathrm{pH}$ represents a large change in hydrogen ion concentration [28]. Changes in $\mathrm{pH}$ can occur due to various reasons; it might be due to the effect of treatment on the biochemical condition of the fruit and slower rate of respiration and metabolic activity [29]. The increase in $\mathrm{pH}$ may be due to the breakdown of acids with respiration during storage [30]. 


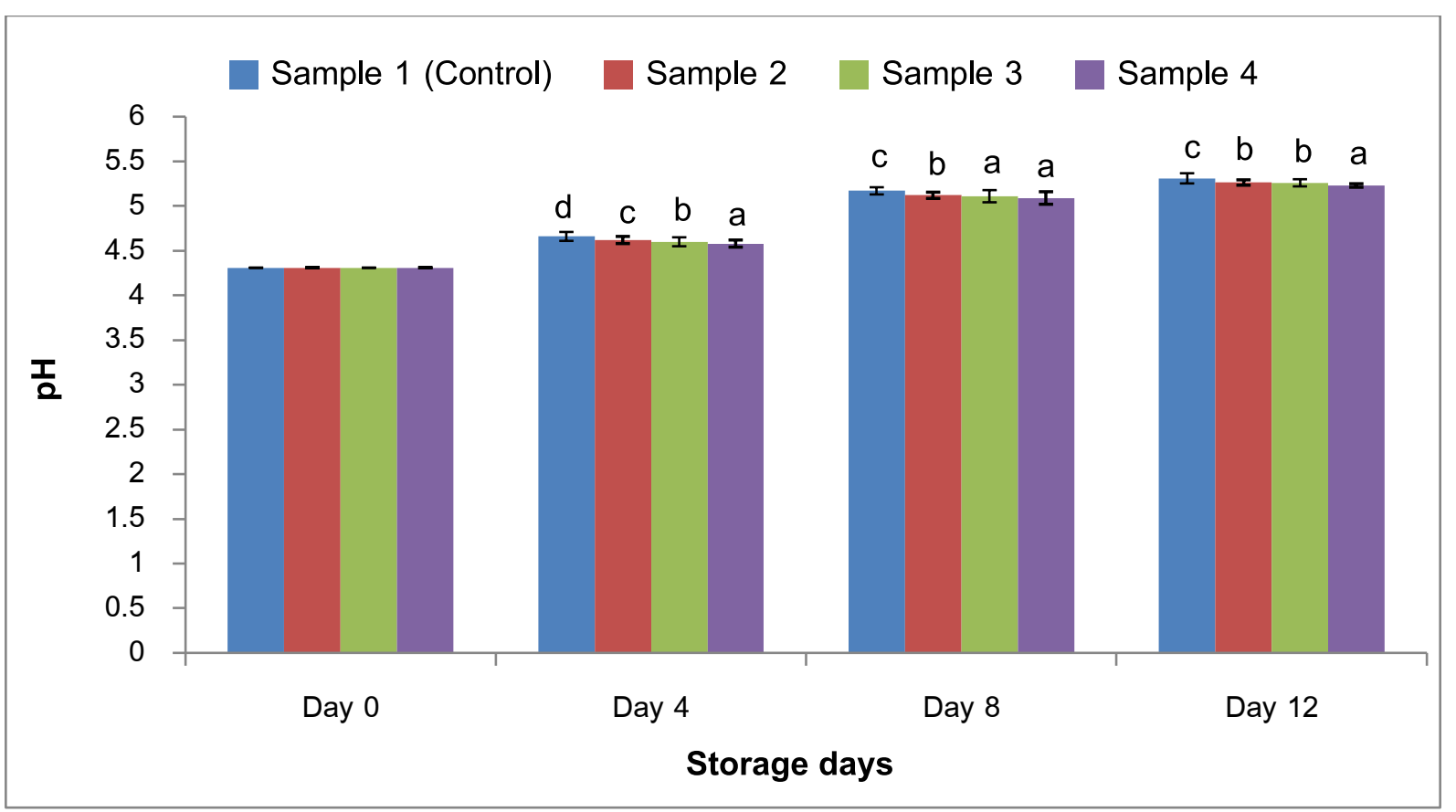

Figure 3: $\mathrm{pH}$ of samples at room temperature $\left(28 \pm 2^{\circ} \mathrm{C}\right)$; Values represent mean \pm standard deviation $(\mathrm{n}=3)$. Means with different letters are significantly different $($ at $\mathrm{p}<0.05)$

\subsubsection{Titratable acidity (\%):}

The titratable acidity of the samples gradually increased over the storage period. The effect of different concentrations of chitosan coating on titratable acidity is shown in figure 4. Titratable acidity of all samples were observed to be $0.35 \%$ in the first day of storage (Day 0). Comparatively better retention of titratable acidity was observed in Sample 4 (1\% chitosan coated bananas) which were $0.36 \%, 0.38 \%$ and $0.386 \%$ at the $4^{\text {th }}, 8^{\text {th }}$ and $12^{\text {th }}$ day of storage respectively. Control samples showed comparatively lower retention of titratable acidity than other samples which were $0.41 \%, 0.44 \%$ and $0.46 \%$ at the $4^{\text {th }}, 8^{\text {th }}$ and $12^{\text {th }}$ day of storage respectively. By the end of the storage (at Day 12), the highest retention of titratable acidity (\%) was observed in Sample 4 i.e. in $1 \%$ chitosan coated bananas $(0.386 \%)$ while the lowest retention of titratable acidity (\%) was observed in Sample 1 i.e. in control samples $(0.46 \%)$. This result indicates that comparatively higher retention of titratable acidity of bananas could be obtained by applying $1 \%$ chitosan coating. This finding complies with the results reported by Ibrahim et al. [24]. It should be noted that treatment of $1 \%$ chitosan coating does not completely inhibit metabolic changes in the fruits, it only reduces the rate of metabolic change. 


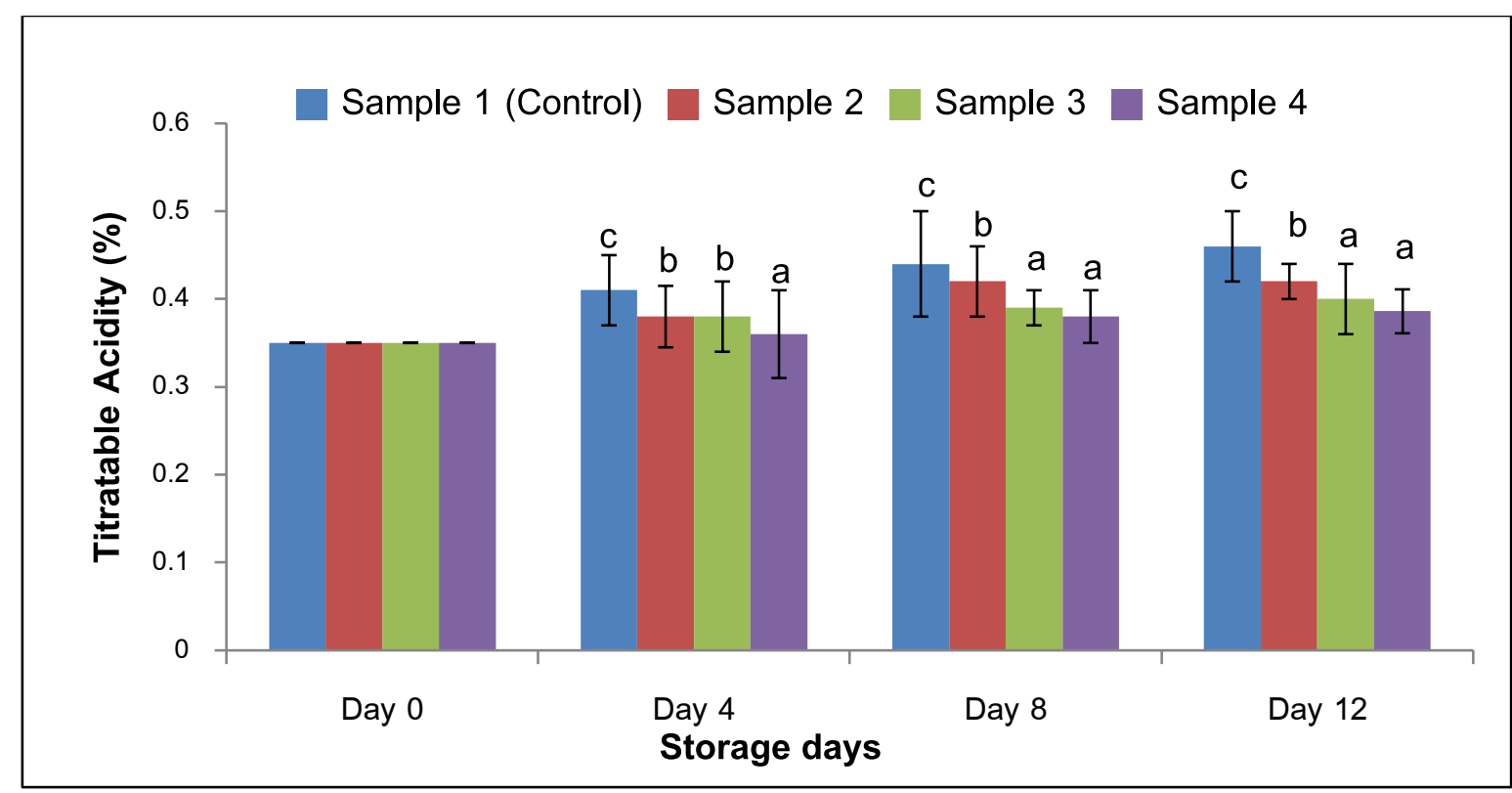

Figure 4: Titratable acidity of samples at room temperature $\left(28 \pm 2^{\circ} \mathrm{C}\right)$; Values represent mean \pm standard deviation $(n=3)$. Means with different letters are significantly different (at $\mathrm{p}<0.05)$

\subsubsection{Disease severity:}

Disease severity of the samples gradually increased from the first day to the end of storage throughout the entire storage period of 12 days. The effect of different chitosan coating on disease severity during storage is illustrated in figure 5. As a postharvest treatment, $1 \%$ chitosan coating showed a significant effect (at $\mathrm{p}$ $<0.05$ ) on reducing the disease severity of banana than other chitosan treatments during the entire storage period (see figure 5). Disease severity score of all samples in the first day of storage (Day 0) was "1", meaning $0 \%$ of fruit surface was rotten in the first day of storage (Day 0). Comparatively lower score of disease severity was observed in Sample 4 (i.e. in $1 \%$ chitosan coated bananas) whose disease severity scores were 1.23, 1.4 and 1.8 at the 4th, 8 th and 12th day of storage respectively. Sample 1 (control samples) showed higher scores of disease severity than other samples which were 2, 3.5 and 4.76 at the 4th, 8th and 12th day of storage respectively. By the end of the storage (at Day 12), the lowest score of disease severity was observed in Sample 4 (disease severity score of 1.8, meaning 0\% of fruit surface was rotten) while the highest score of disease severity was observed in control samples (disease severity score of 4.76, meaning 51-75\% of fruit surface was rotten). This result implies that comparatively lower disease severity of bananas could be attributed to the application of $1 \%$ chitosan coating. This finding is in agreement with the results reported by Ibrahim et al. [24] and Jitareerat et al. [29]. The protective layer of chitosan coating might have helped to maintain the quality of bananas. Li \& Yu [31] revealed that treatment of $0.5 \%$ and $1 \%$ chitosan coating considerably decreased the incidence of brown rot in peach which is caused by Monilinia fructicola and delayed disease development. Feliziani et al. also reported that application of $1 \%$ chitosan coating mitigated the development of postharvest disease in sweet cherry [32]. 


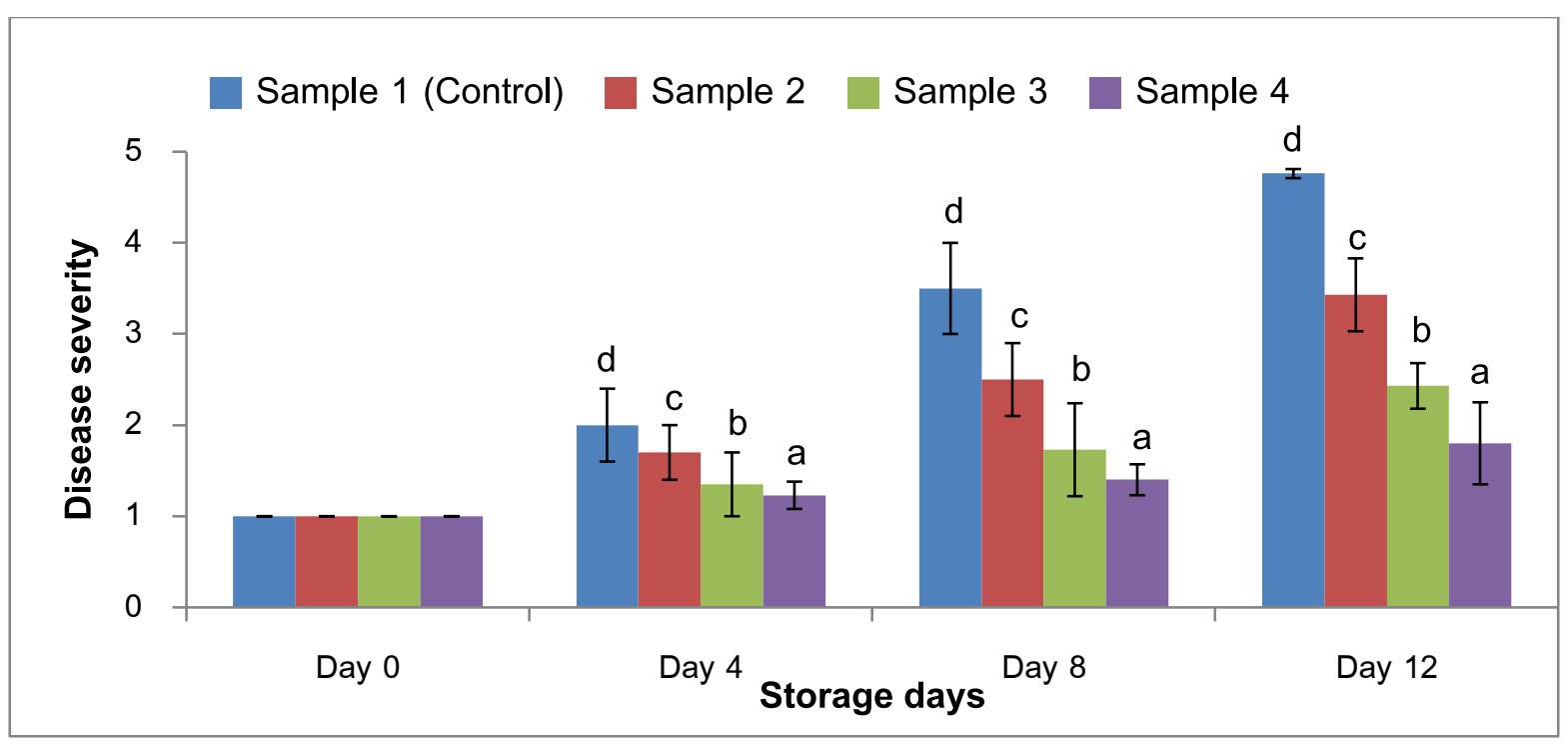

Figure 5: Disease severity of samples at room temperature $\left(28 \pm 2^{\circ} \mathrm{C}\right)$; Values represent mean \pm standard deviation $(\mathrm{n}$ $=3$ ). Means with different letters are significantly different (at $p<0.05)$

\subsubsection{Shelf life:}

The effect of different chitosan coating on the shelf life of banana during storage is shown in figure 6 . The maximum shelf life of banana was recorded to be 16 days in Sample 4 (i.e. in 1\% chitosan coated bananas) while the shortest shelf life was observed to be 12 days in Sample 1 (i.e. in untreated bananas). The shelf life of Sample 2 (0.5\% chitosan coated bananas) and Sample 3 (0.75\% chitosan coated bananas) was recorded to be 13 days and 15 days respectively. The above results led to the conclusion that chitosan coating considerably influenced the shelf life of banana and $1 \%$ chitosan coating was more suitable for extending the shelf life of bananas than other treatments.

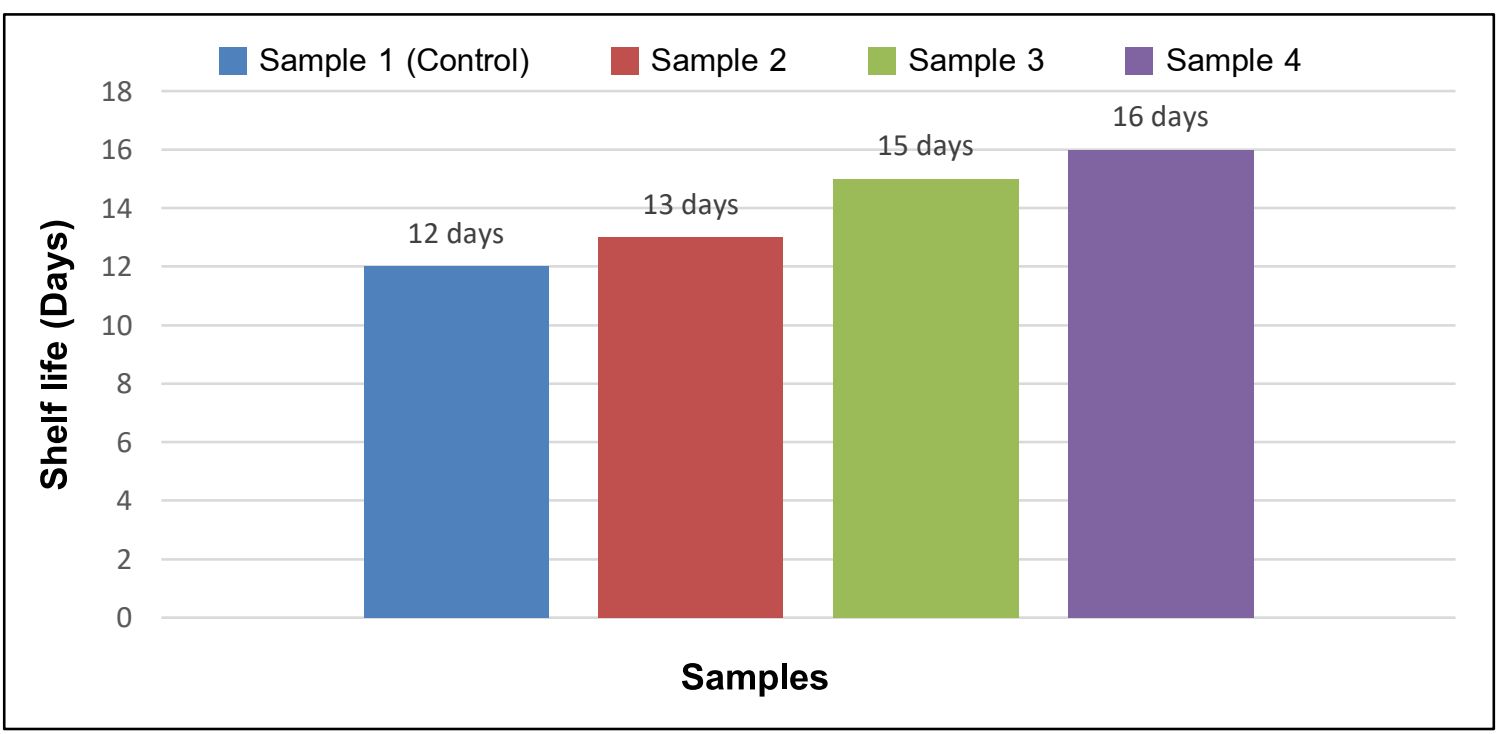

Figure 6: Shelf life of samples at room temperature $\left(28 \pm 2^{\circ} \mathrm{C}\right)$ 


\section{CONCLUSION}

The maximum retention of total weight loss $(\%)$, total soluble solids ( $\left({ }^{\circ}\right.$ Brix $), \mathrm{pH}$, titratable acidity (\%) and disease severity of banana samples were reported to be $21.66 \%, 19.7^{\circ}$ Brix, $5.23,0.46 \%$ and 1.8 respectively which was found in $1 \%$ chitosan coated bananas. The maximum prolonged shelf life of 16 days was also observed in $1 \%$ chitosan coated bananas. Therefore, it should be concluded that $1 \%$ chitosan is remarkably efficient as an edible coating material in preventing post-harvest spoilage (losses) of matured banana by enhancing their overall quality during storage. The methodology developed in this study offers an alternative approach to extend the shelf life of banana by extracting chitosan from shrimp shell and utilizing it as an edible coating to reduce the post-harvest losses of banana in efficient way nicely.

\section{ACKNOWLEDGEMENTS}

The authors are grateful to the Department of Food Engineering and Tea Technology, Shahjalal University of Science and Technology for continuous material support and technical assistance.

\section{REFERENCES}

[1] Menezes, E. W., Tadini, C. C., Tribess, T. B., Zuleta, A., Binaghi, J., Pak, N., ... \& Lajolo, F. M., "Chemical composition and nutritional value of unripe banana flour (Musa acuminata, var. Nanicão)". Plant foods for human nutrition, 66(3), 231-237, 2011.

[2] Bangladesh Bureau of Statistics, "Yearbook of agricultural statistics-2017". 29th Series, Published by: Statistics and Informatics Division (SID), Ministry of Planning, Government of the People's Republic of Bangladesh, pp. 200, 2018.

[3] Hossain, M. A., "Postharvest loss assessment of major fruits grown in the hill region of Bangladesh". Bangladesh Journal of Agriculture 42(1): 171-184, 2017.

[4] Malmiri, J. H., Osman, A., Tan, C. P., \& Rahman, A. R., "Evaluation of effectiveness of three cellulose derivative-based edible coatings on changes of physico-chemical characteristics of 'Berangan' banana (Musa sapientum cv. Berangan) during storage at ambient conditions". International Food Research Journal 18(4), 1381, 2011.

[5] Li, P., \& Barth, M. M., "Impact of edible coatings on nutritional and physiological changes in lightlyprocessed carrots". Postharvest Biology and Technology 14(1), 51-60, 1998.

[6] Thompson, A. K., "Postharvest treatments", In: Fruit and vegetables. Ames, Iowa: Blackwell Publishing Ltd., pp. 47-52, 2003.

[7] Debeaufort, F., Quezada-Gallo, J. A., \& Voilley, A., "Edible films and coatings: tomorrow's packagings: a review". Critical Reviews in Food Science 38(4): 299-313, 1998.

[8] Saputra, K. A., Angela, A., Surya, R., \& Gifsan, Y., "Application of chitosan as preservatives on organic fruits". Asian Journal of Food and Agro-Industry 2: 221-227, 2009.

[9] Vargas, M., Albors, A., Chiralt, A., \& González-Martínez, C., "Characterization of chitosan-oleic acid composite films". Food Hydrocolloids 23(2): 536-547, 2009.

[10] El Ghaouth, A., Arul, J., Ponnampalam, R., \& Boulet M., "Chitosan coating effect on storability and quality of fresh strawberries". Journal of food science 56(6): 1618-1620, 1991.

[11] Zhang, D., \& Quantick, P. C., "Effects of chitosan coating on enzymatic browning and decay during postharvest storage of litchi (Litchi chinensis Sonn.) fruit". Postharvest Biology and Technology 12(2), 195-202, 1997.

[12] Jiang, Y., Zhang, Z., Joyce, D. C., \& Ketsa, S., "Postharvest biology and handling of longan fruit (Dimocarpus longan Lour.)". Postharvest Biology and Technology 26(3), 241-252, 2002.

[13] Pesis, E., Dvir, O., Feygenberg, O., Arie, R. B., Ackerman, M., \& Lichter A., "Production of acetaldehyde and ethanol during maturation and modified atmosphere storage of litchi fruit". Postharvest Biology and Technology 26(2), 157-165, 2002. 
[14] Toan, N. V., "Production of chitin and chitosan from partially autolyzed shrimp shell materials". The open biomaterials journal 1(1), 2009.

[15] AOAC International. Aromatic intermediates and derivatives. In Official Methods of Analysis of AOAC International, 19th ed.; Latimar, G.W., Ed.; Association of Official Analytical Chemists: Washington, DC, USA, 2012; pp. A.IV.1-A.IV.17, ISBN1 0935584838; ISBN2 9780935584837.

[16] Puvvada, Y. S., Vankayalapati, S., \& Sukhavasi, S., "Extraction of chitin from chitosan from exoskeleton of shrimp for application in the pharmaceutical industry". International Current Pharmaceutical Journal 1(9), 258-263, 2012.

[17] Domard, A., \& Rinaudo, M., "Preparation and characterization of fully deacetylated chitosan". International Journal of Biological Macromolecules 5(1), 49-52, 1983.

[18] No, H. K., \& Meyers, S. P., "Preparation and characterization of chitin and chitosan: a review". Journal of aquatic food product technology 4(2), 27-52, 1995.

[19] Suseno, N., Savitri, E., Sapei, L., \& Padmawijaya, K. S., "Improving shelf-life of cavendish banana using chitosan edible coating". Procedia Chemistry, 9, 113-120, 2014.

[20] Maqbool, M., Ali, A., Alderson, P. G., Zahid, N., \& Siddiqui, Y., "Effect of a novel edible composite coating based on gum arabic and chitosan on biochemical and physiological responses of banana fruits during cold storage". Journal of agricultural and food chemistry, 59(10), 5474-5482, 2011.

[21] Shao, X. F., Tu, K., Tu, S., \& Tu, J., "A combination of heat treatment and chitosan coating delays ripening and reduces decay in "Gala" apple fruit". Journal of food quality 35(2), 83-92, 2012.

[22] Dang, Q. F., Yan, J. Q., Li, Y., Cheng, X. J., Liu, C. S., \& Chen, X. G., "Chitosan acetate as an active coating material and its effects on the storing of Prunus avium L.". Journal of food science 75(2), S125S131, 2010.

[23] Moazzem, M., Sikder, M., Hossain, B., \& Zzaman, W., "Shelf-Life Extension of Wood Apple Beverages Maintaining Consumption-Safe Parameters and Sensory Qualities". Beverages, 5(1), 25, 2019.

[24] Ibrahim, S. M., Nahar, S., Islam, J. M., Islam, M., Hoque, M. M., Huque, R., \& Khan, M. A., "Effect of low molecular weight chitosan coating on physico-chemical properties and shelf life extension of pineapple (Ananas sativus)". Journal of forest products \& industries, 3(3), 161-166, 2014.

[25] Vargas, M., Pastor, C., Chiralt, A., McClements, D. J., \& Gonzalez-Martinez, C., "Recent advances in edible coatings for fresh and minimally processed fruits". Critical Reviews in Food Science and Nutrition 48(6), 496-511, 2008.

[26] Das, D. K., Dutta, H., \& Mahanta, C. L., "Development of a rice starch-based coating with antioxidant and microbe-barrier properties and study of its effect on tomatoes stored at room temperature". LWT-Food Science and Technology 50(1), 272-278, 2013.

[27] Ali, A., Muhammad, M. T. M., Sijam, K., \& Siddiqui, Y., "Effect of chitosan coatings on the physicochemical characteristics of Eksotika II papaya (Carica papaya L.) fruit during cold storage". Food chemistry 124(2), 620-626, 2011.

[28] Ball, J. A., "Evaluation of two lipid-based edible coatings for their ability to preserve post-harvest quality of green bell peppers". Doctoral dissertation, Virginia Tech, pp. 8-9, 1997.

[29] Jitareerat, P., Paumchai, S., Kanlayanarat, S., \& Sangchote, S., "Effect of chitosan on ripening, enzymatic activity, and disease development in mango (Mangifera indica) fruit". New Zealand journal of crop and horticultural science 35(2), 211-218, 2007.

[30] Pesis, E., Dvir, O., Feygenberg, O., Arie, R. B., Ackerman, M., \& Lichter, A., "Production of acetaldehyde and ethanol during maturation and modified atmosphere storage of litchi fruit". Postharvest Biology and Technology 26(2), 157-165, 2002.

[31] Li, H., \& Yu, T., "Effect of chitosan on incidence of brown rot, quality and physiological attributes of postharvest peach fruit". Journal of the Science of Food and Agriculture 81(2), 269-274, 2001.

[32] Feliziani, E., Santini, M., Landi, L., \& Romanazzi, G. "Pre-and postharvest treatment with alternatives to synthetic fungicides to control postharvest decay of sweet cherry". Postharvest Biology and Technology 78, 133-138, 2013. 